Article

\title{
Libros en Mano: Phonological Awareness Intervention in Children's Native Languages
}

\author{
Wendy Gonzales * and Marie Tejero Hughes 1 \\ Department of Special Education, University of Illinois at Chicago, Chicago, IL 60607, USA; marieth@uic.edu \\ * Correspondence: wmarti6@uic.edu
}

Received: 20 August 2018; Accepted: 17 October 2018; Published: 19 October 2018

check for updates

\begin{abstract}
The growing diversity in schools in the United States resulting from the rising number of English learners (ELs) has put more pressure on both children and teachers. Teachers are faced with the challenge of meeting the educational needs of culturally and linguistically diverse (CLD) learners, including the unique needs of CLD children with academic delays or disabilities. As early as preschool, many ELs are performing academically lower than their monolingual peers in literacy, and the gap can be even greater for ELs identified as having a delay or disability. However, providing explicit phonological awareness interventions in the child's native language may help improve English reading outcomes and mediate the negative effects on reading achievement attributed to limited English proficiency. This intervention study looked at how a phonologically based emergent literacy intervention provided in Spanish to four EL preschoolers affected their emergent literacy and phonological awareness outcomes in English and Spanish. All of the children increased their overall emergent literacy and phonological awareness skills in both English and Spanish. The findings indicated that all four children showed some increase in English phonological awareness skills in both syllable segmentation and letter sound knowledge, while sound isolation and sound segmentation demonstrated mixed results across participants.
\end{abstract}

Keywords: early intervention; English language learners; Spanish; phonological awareness; emergent literacy

\section{Introduction}

About 12 million children in the schools in the United States (US) are considered as having a limited English proficiency, designating them as English learners (ELs) [1]. Due to this growing diversity, teachers are now faced with the additional challenge of meeting the educational needs of culturally and linguistically diverse (CLD) learners, including those with academic delays and disabilities. Likewise, ELs are tasked with learning academic content while simultaneously learning English, which may result in many ELs experiencing more barriers to learning than other children [2].

The achievement gap for ELs is a real and persistent problem in schools across the United States. As early as kindergarten, compared to monolingual students, only $17 \%$ of ELs' scores are in the average range on measures of language arts, math, and general knowledge. This gap continues to widen throughout the elementary school years [3]. The continuation of the achievement gap throughout school leads to higher dropout rates, with only 63\% of ELs graduating from high school [4], and contributes to ELs leaving school as early as eighth grade [5]. However, there is widespread agreement in the field that effective early literacy instruction can minimize the long-term difficulties ELs experience [6].

Teachers, unsure if an EL's academic difficulties are the result of their limited English or a possible learning disability, are hesitant to provide necessary intensive interventions [3,7]. This confusion is in part due to a lack of intervention services in earlier grades. ELs who continue to struggle after third 
grade tend to be referred more often to special education [3]. As a result, there is a tendency towards the overrepresentation of ELs within special education [8]. Compared to the average of $9 \%$ of all US children identified as needing special education services, some states reported as many as $17.3 \%$ of their ELs as being identified as needing special education services [8].

\subsection{Native Language Literacy Instruction}

Theoretical and empirical evidence indicates that literacy development in the native language promotes English literacy acquisition $[9,10]$. This finding is particularly true with languages that have demonstrated cross-linguistic transfer [11]. Unfortunately, many Spanish-speaking children enter school with lower literacy achievement than same-age monolingual peers, even in their native language [12]. However, children who enter school with strong skills in their native language are able to transfer those skills while learning English [11]. This cross-linguistic transfer occurs when children access and use their knowledge from their native language and apply it to the new language they are learning $[13,14]$. For example, children may use their understanding of letter-sounds of their native language and apply them to letters of the English alphabet. Solid language abilities, particularly in vocabulary and conceptual knowledge, in the native language are foundational for stronger achievement in English in elementary school and beyond [12]. For children not exposed to these concepts at home, language of instruction, particularly instruction in the primary language, helps facilitate the acquisition of necessary vocabulary and conceptual knowledge.

Research has indicated that a strong foundation in a child's native language is valuable for acquisition of English [15]. In addition, there is considerable evidence that indicates that ELs enrolled in bilingual programs achieve as well, or even better, than those in English-only programs [16]. Indeed, explicit instruction in foundational skills in Spanish may assist children's transition to reading in English [13]. There is limited research on the use of native language instruction to support the growth of English outcomes, and the research available has shown mixed results, with some studies showing positive effects on English outcomes, for example, in the study by Vaughn et al. [17]. In general, studies that used Spanish as the language of instruction and examined its impact on English outcomes found that training in phonological awareness (PA) helps students make gains in Spanish. However, gains in English were not as consistent in some studies, for example, in $[18,19]$. Additionally, research indicates that children instructed bilingually for at least three years, beginning in kindergarten, made more growth in language and literacy than those whose foundational education (preschool) was provided in English [10]. This is also the case for ELs who are struggling with literacy, in that bilingual instruction appears to benefit them even more than other ELs [20]. Unfortunately, children who were solely instructed in English experienced attrition of their native language abilities [12]. Children with limited academic proficiency in both their native language and English have fewer reference points from which to pull from and learning to read becomes an increasingly more difficult task.

\subsection{Emergent Literacy}

Emergent literacy, as defined by the National Early Literacy Panel [21], are the skills young children begin to develop as they become literate. These include print knowledge (concepts about print and the alphabet), PA, writing (inventive spelling), and oral language (grammar, vocabulary, and narrative). These skills help predict future reading achievement of ELs [22]. Although the statistics for reading outcomes for ELs are daunting, effective literacy instruction that includes enrichment of the native language can help children meet grade level expectations [22]. Numerous studies on reading acquisition of ELs and emergent literacy development have been carried out, for example, in [23]; however, as Chan and Sylva [24] point out, when it comes to how to best instruct young ELs, the research has limited convergence. However, the evidence available does indicate that ELs with difficulties in reading do seem to follow a similar path toward early literacy development to English speakers [25]. 
The research on emergent literacy has shown to be effective across settings and programs; however, the research with ELs is limited [26]. As an example, a study with preschool children focused on an emergent literacy intervention noted that the intervention group did better than the control group on measures of emergent literacy by the time the school year ended, but as is typical of many studies, ELs were not represented in the intervention group [27]. Hilbert and Eis [26] replicated the study and included ELs and students with disabilities. Their intervention found that EL students and students with disabilities in the intervention group did significantly better on measures of picture naming and had significant increases in print knowledge and vocabulary, thus highlighting the benefits of the intervention with these additional populations. The need to address the emergent literacy difficulties of young ELs is made easier given that emergent literacy skills have been found to transfer across languages [28]. The specific domains that transfer include PA, syntactic awareness, functional awareness, decoding, the use of formal definitions and decontextualized language, knowledge of writing conventions and story grammar, and meaning-making comprehension strategies [28]. By strengthening these areas in the native language, ELs can be more prepared to learn to read in English.

\subsection{The Role of Phonological Awareness}

PA is an important component in reading development that focuses on children's ability to identify and manipulate units of sounds [21]. Research has found that PA is a foundational skill in learning to read, not only in English, but in other alphabetic languages as well [13]. PA interventions in English have been shown to have significant effects on young ELs' PA and have better effects than other interventions that focus on vocabulary or comprehension [3]. PA, alphabet knowledge, and word recognition measures acquired at the beginning of first grade were predictive of reading levels at the end of each grade level from first to third grade [29]. Additionally, research has shown, in general, that the Spanish PA of young ELs strongly predicts their PA ability in English [30]. There is also strong evidence that suggests PA skills transfer from the native language to English [31] and that PA instruction in English supports the development of the skill in Spanish [32]. As a study by Cardenas-Hagan and colleagues [13] found, students with limited English skills in letter name and sound identification, PA, and oral language did better when their skills in Spanish were strong. The language of instruction is also a predictor of Spanish word reading, decoding of pseudo words, and English word reading; however, differences in ability to decode in Spanish and English are accounted for by phonological processes [33]. Researchers have also determined that later PA (segmenting and blending) was the strongest predictor for all measures of decoding, and earlier PA (identifying rime and onset) was the second most significant predictor.

Even when provided with support in English, ELs further benefit from phonologically based interventions [34]. Another study that compared interventions that provided PA training to second graders with significant reading difficulties in contextualized and decontextualized formats also found that the intervention groups made significant gains in PA and word identification skills [35]. Similarly, ELs are able to catch up to their monolingual peers after PA instruction [36], and children with stronger phonological abilities make better progress in literacy [37].

\subsection{Purpose of Study}

Although fewer ELs are placed into special education as a result of response to intervention (RTI) [7], little research is available on effective interventions for ELs or the use of reading interventions in the native language (for an example, see [38]). Providing explicit PA interventions in the child's native language may help improve English reading outcomes and mediate the negative effects on reading achievement attributed to limited English proficiency. Therefore, this pilot study was designed to determine how a short-term phonologically based emergent literacy intervention provided in Spanish impacts children's emergent literacy and phonological skills in Spanish and English. This study addresses the following research question: Do Spanish speaking preschool ELs who have 
difficulties with emergent literacy improve their PA and emergent literacy skills in Spanish and English when provided with small-group, phonologically based emergent literacy instruction in Spanish?

\section{Materials and Methods}

\subsection{Participants}

Four EL preschoolers ( 3 boys, 1 girl) were recruited from a family community center located in a predominately Mexican immigrant neighborhood of a large Midwestern city. The center offered Head Start services to children between the ages of three and five. Six Head Start teachers were asked to nominate ELs who were at least 4 years old and who struggled with literacy skills based on curriculum-based measures and professional judgment. The teachers identified children for the study and sent home information about the study. A total of seven parents of 4- and 5-year-olds nominated by the teachers indicated they were interested and agreed to have their child participate in the study. The children were then screened to verify limited proficiency with the English language, as determined by the English Pre-IDEA Oral Proficiency Test (Pre-IPT) and subsequent difficulties with literacy with a score of 9 or less on the Preschool Literacy and Numeracy (PLN) performance task (see Table 1). A score of 9 indicated the child was below mastery according to the assessment manual. Two children who scored high on the PLN were determined to be ineligible. In addition, one child who met eligibility criteria was withdrawn from the study prior to completion due to poor attendance.

Table 1. Children's eligibility information.

\begin{tabular}{cccc}
\hline & Age & PRE-IPT & PLN \\
\hline Ignacio & 4.4 & B & 8 \\
Ricardo & 4.6 & B & 9 \\
Manuel & 5.5 & B & 9 \\
Paula & 5.6 & B & 0 \\
\hline
\end{tabular}

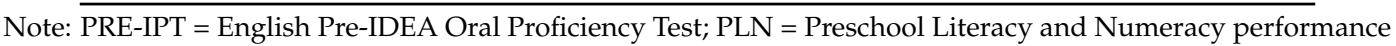
task; $\mathrm{B}=$ non-English speaking.

\subsection{Instruments}

\subsubsection{English Pre-IDEA Oral Proficiency Test (Pre-IPT)}

The Pre-IPT is a standardized test that measures vocabulary, syntax, discourse, and pragmatics in English [39]. It is used to screen a child's English language proficiency. The assessment involves the use of a picture board depicting a birthday party at a park. At each level, children are asked to respond to more and more complex questions in English. Depending on the child's level of proficiency, this test can take between three and $10 \mathrm{~min}$. The test-retest reliability of Pre-IPT is 0.77 [39]. Simple vocabulary, such as being able to state their name and gender, is measured in Levels A and B, and children who score at this level are designated as Non-English Speaking. In Levels C and D, children are asked more complex questions and are expected to have lengthier responses. Children who score at these levels are designated as Limited English Speaking. Finally, at Level E, children are asked to tell a short story about going to a party. Children who score at Level E are considered fully English Proficient.

\subsubsection{Preschool Literacy and Numeracy Performance Task (PLN)}

The PLN is an educator-created performance task that the teachers in the district developed. The PLN is used by all teachers in the local school district to determine mastery, or progress towards mastery, of a state learning standard that focuses on the organization and basic features of print. The PLN has the child distinguish between letters and numbers, demonstrate direction of reading, and identify book concepts such as page turning. The 5-item performance task is administered individually and takes five minutes to complete. All items are scored on a rubric with points ranging from 0 to 3. One item, which focuses on print tracking and page turning, is scored from 0-6 points. 
Points are added together to get a final score with a maximum score of 18 . No psychometric information regarding reliability of the assessment is provided by the district. To be eligible for the study, a child had to have a total score of 9 or less, which indicated a lack of mastery of the concepts as determined by district guidelines.

\subsubsection{Get Ready to Read! Screener (GRR)}

The GRR is a brief assessment of preschoolers' knowledge of emergent literacy that is needed for successful reading later in their schooling [40]. The English and Spanish assessment contains 25 items that ask the child to choose the answer to a question from among four pictures. In both versions, items cover concepts about print (e.g., which picture shows the name of the cereal?), letter knowledge, and early writing (13 items in English; 10 items in Spanish), while the remaining items assess PA (12 items in English; 15 items in Spanish) [40]. Items on the Spanish version were similar to the English version but took into account language differences and were not just direct translations. Children scoring between zero and six points are said to have very weak skills; those who score between 21 and 25 have very strong skills. Reliability of internal consistency for the GRR is reported as an overall alpha of 0.78 for the English screener and 0.76 for the Spanish screener [40]. Each version of the GRR took $10 \mathrm{~min}$ to individually administer and were completed at pretest and posttest.

\subsubsection{Prereading Inventory of Phonological Awareness (PIPA)}

This English inventory looks at six areas of PA: rhyme awareness, matching two pictures that rhyme, alliteration awareness, matching two pictures with the same initial sounds, syllable segmentation, breaking up a word into syllables, sound isolation, isolating initial sounds, sound segmentation, segmenting words into individual phonemes, and letter-sound knowledge, identifying the letters or sounds of the alphabet [41]. The inventory was administered at pretest and posttest to each child individually, with each subtest taking about five minutes to administer, for a total of $30 \mathrm{~min}$. Each subtest has 12 items, except for the letter-sound knowledge subtest, which has 32 items. Scores on the subtests are typically reported as percentiles, with emerging/below basic level in the 0 to 29th percentile, basic level between the 30th and 69th percentile, and proficient level in the 70th to 99th percentile [41]. Test-retest reliability for each subtest is as follows: rhyme awareness $=0.80$, syllable segmentation $=0.67$, alliteration $=0.83$, sound isolation $=0.94$, sound segmentation $=0.83$, and letter-sound knowledge $=0.97$ [41].

\subsubsection{Fluidez en la Segmentacion de Fonemas (FSF)}

This Spanish phonemic awareness assessment determines a child's skill to segment one-, two-, and three-syllable words [42]. Words are presented orally, and children are asked to say the individual phonemes for the word. For example, for the word "gato" the child would say /g/ /a/ / t/ /o/. Points are given for each phoneme produced correctly [39]. Students who achieve 15 points or more are considered to have a low risk of reading difficulty, while students who score less than 14 points are considered at risk. Alternate-form reliability is reported as 0.65 for this measure [43]. The FSF was administered individually at pretest and posttest, with each administration taking a minute.

\subsection{Procedures}

Participation in this study involved a two-step process; consent and then screening. After the Institutional Review Board of the University approved the study, recruitment for participants began. Once parents signed the permission form and the child agreed to participate, then an eligibility session was scheduled. The eligibility session took $25 \mathrm{~min}$ per child and resulted in two children not qualifying due to high scores on the PLN. Five children qualified and participated in the intervention; however, one child was withdrawn from the study due to poor attendance (more than six absences).

Pretest data was obtained on two different days, with each individual session lasting $30 \mathrm{~min}$. On the first day, children started with the English version of the GRR and completed PIPA subtest 
1 through 3. The last three subtests of the PIPA were administered on the second day, as was the Spanish version of the GRR. The FSF was administered at the first intervention session. Posttest data was obtained over two days after the completion of the intervention. All data was collected by the researcher and data results are found in Tables 2 and 3.

Table 2. Pre- and posttesting for Get Ready to Read!

\begin{tabular}{lccccccc}
\hline & & \multicolumn{3}{c}{ English } & \multicolumn{3}{c}{ Spanish } \\
\hline \multirow{3}{*}{ Ignacio } & Pre & Post & Change & Pre & Post & Change \\
& ER & 6 & 8 & +2 & 7 & 7 & 0 \\
& PA & 3 & 5 & +2 & 7 & 9 & +2 \\
& Total & 9 & 13 & +4 & 14 & 16 & +2 \\
\multirow{5}{*}{ Manuel } & ER & 9 & 9 & 0 & 7 & 8 & +1 \\
& PA & 3 & 7 & +4 & 7 & 9 & +2 \\
& Total & 11 & 16 & +4 & 14 & 17 & +3 \\
& ER & 5 & 9 & +4 & 3 & 6 & +3 \\
& PA & 5 & 6 & +1 & 9 & 9 & 0 \\
& Total & 10 & 15 & +5 & 12 & 15 & +3 \\
& ER & 4 & 3 & -1 & 1 & 3 & +2 \\
& PA & 4 & 4 & 0 & 8 & 8 & 0 \\
& Total & 8 & 7 & -1 & 9 & 11 & +2 \\
\hline
\end{tabular}

Notes: All scores are reported as raw scores; $\mathrm{ER}=$ emergent reading; $\mathrm{PA}=$ phonological awareness.

Table 3. Pre- and post-testing for PIPA.

\begin{tabular}{cccccccc}
\hline \multirow{2}{*}{ Ignacio } & Pre & $\begin{array}{c}\text { Rhyme } \\
\text { Awareness }\end{array}$ & $\begin{array}{c}\text { Syllable } \\
\text { Segmentation }\end{array}$ & $\begin{array}{c}\text { Alliteration Sound } \\
\text { Awareness }\end{array}$ & $\begin{array}{c}\text { Sound } \\
\text { Isolation }\end{array}$ & $\begin{array}{c}\text { Letter Sound } \\
\text { Segmentation } \\
\text { Knowledge }\end{array}$ \\
& Post & 5 & 0 & 2 & 0 & 0 & 0 \\
& Change & +3 & +8 & +2 & 0 & 0 & 2 \\
\multirow{5}{*}{ Manuel } & Pre & 3 & 3 & 2 & 0 & 0 & +2 \\
& Post & 2 & 7 & 2 & 0 & 2 & 1 \\
& Change & -1 & +4 & 0 & 0 & +2 & +1 \\
& Pre & 1 & 1 & 4 & 0 & 0 & 2 \\
& Post & 3 & 7 & 4 & 1 & 0 & +2 \\
& Change & +2 & +6 & 0 & +1 & 0 & 0 \\
& Pre & 3 & 6 & 3 & 4 & 0 & 2 \\
& Post & 4 & 8 & 3 & 2 & 3 & +2 \\
\hline
\end{tabular}

\subsubsection{Intervention}

Children were placed into two small groups by order of their eligibility. Twelve 25-min sessions were conducted for three consecutive days over a four-week period with each of the groups. Two of the children completed all the sessions, and two completed 11 sessions over the course of the intervention. During each session, which followed a similar structure each time (see Table 4 for sample lesson plan), children were engaged in literacy activities in Spanish that revolved around a storybook. Four books were used (one per week): Sali de Paseo [44], El Canguro Tiene Mama? [45], A Sembrar Sopa de Verduras [46], and Como Crece Una Semilla [47]. Sessions began with recitation of the alphabet song in Spanish, followed by eight minutes of interactive PA activities. The phonemic awareness activities were designed to help increase students' awareness of sounds. This is consistent with research indicating that PA interventions are helpful for students, since they lead to decoding [48]. Although PA was the prior focus of the intervention, other activities were included during the session as part of the phonologically based emergent literacy intervention. Thus, two vocabulary words were introduced on the first day of each intervention week that were related to the book. Children engaged in vocabulary 
work for $5 \mathrm{~min}$ by finding examples of the word, drawing pictures about the word, and dictating sentences about the word. Shared storybook reading activities followed for about $8 \mathrm{~min}$. Sessions concluded with individual PA progress monitoring while other children engaged with books. Each intervention session was high-paced and children were actively engaged throughout.

Table 4. Sample lesson plan.

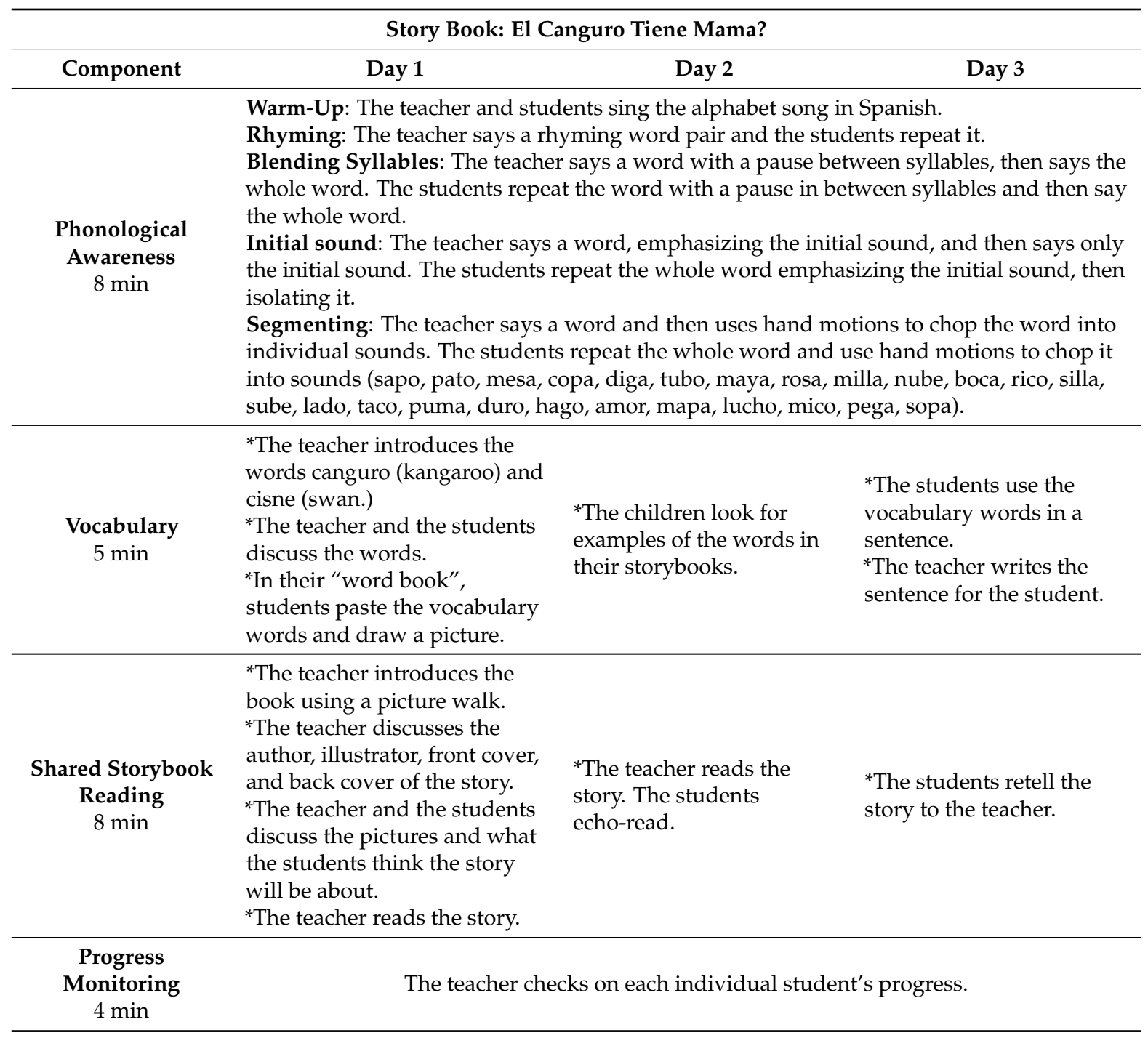

\subsubsection{Data Analysis}

Due to the small sample size, pre- and posttest results were analyzed using descriptive statistics instead of more advanced and inferential analyses and calculations.

\section{Results}

\subsection{Pre- and Posttests}

On the GRR Spanish assessment (see Table 2), all the children increased their total scores on average by 2.5 points (out of 25 points), with most children showing growth on the emergent literacy subscale of the assessment. The GRR English assessment showed growth for all the children except one. For children who did improve their total score, the increase from pretest to posttest averaged 4.33 points, with three children showing growth in PA and two in emergent literacy. Growth on the PIPA (see Table 3), which was administered in English, depended on the subtest, with all children 
showing growth on the syllable segmentation, with an average of 5 points (out of 12) across the children. In addition, all children also showed gains on the letter sound knowledge, with an average of 1.75 points' growth (out of 32). On the other subtests, results varied by child, with three children showing growth on rhyme awareness and two children improving their sound segmentation. However, only one child showed improvement on alliteration or sound isolation. As far as the FSF, which was administered in Spanish, all the children scored a zero at the start of the intervention. Afterward, two children demonstrated growth with an average of 5.5 points, while the other children showed no growth.

\subsection{Ignacio}

Ignacio was a 4-year-4-month-old Latino preschooler who was instructed in a general education classroom in Spanish by a bilingual teacher. There were two aides in the room, both of which were bilingual. Posttests indicate that he made gains in his emergent literacy and PA abilities. During the pretest, Ignacio had difficulty identifying parts of a book, sounds, rhyming, and functions of print. During the posttest, in English, he was able to identify letters, the letter that says /s/, identify the picture that rhymes with ball, and identify the back of the book, thus increasing his score by four points. In Spanish, Ignacio's PA also grew, particularly in rhyme awareness, syllable segmentation, alliteration, and letter sound knowledge (see Table 3). Ignacio did not show growth in sound isolation or segmentation. Ignacio had difficulty identifying single consonant sounds/graphemes, such as in fish and cake, vowels as in elephant, and a consonant cluster as in plane. In sound segmentation, Ignacio had difficulty with one-sound-to-one-letter correspondence as well as one-sound-to-two-letter correspondence. On the FSF, Ignacio showed no growth, but he was able to segment the words into syllables; for example, when asked to say the sounds in mano (hand), Ignacio said /ma/-/no/.

\subsection{Ricardo}

Ricardo was a 4-and-a-half-year-old Latino preschooler who was instructed in a general education classroom in English by a monolingual teacher. There were two aides in the room, both of which were bilingual. Posttests indicate that he made gains in his emergent literacy and PA abilities. At the pretest, Ricardo had difficulty identifying letter sounds, initial sounds, rhyming, blending, and determining best forms of writing. At the end of the twelve sessions, Ricardo's emergent literacy in English had grown in both English and Spanish. On the PIPA, Ricardo made the most growth in syllable segmentation (see Table 2 for scores). Ricardo continued to show difficulty with initial sound identification and rhyming, but he was able to blend syllables together, identify initial sounds, and determine what good writing looks like. Although the FSF showed no growth for Ricardo, he did move from repeating the words spoken out-loud for the probe to breaking the words up into syllables. This is a typical decoding skill for reading in Spanish and a precursor skill to individual phoneme segmentation.

\subsection{Manuel}

Manuel was a 5-year-5-month-old Latino preschooler who was instructed in a general education classroom in Spanish by a bilingual teacher. There were two aides in the room, both of which were bilingual. At pretest, Manuel had difficulty identifying letters, words, letter sounds, rhyming pairs, and in blending syllables. At posttest, Manuel continued to show difficulty with rhyming and identifying best forms of writing; however, he did show growth in both English and Spanish (see Table 3). The results of his PIPA indicate the most growth in syllable segmentation and rhyme awareness. On the FSF assessment, he showed a growth of 8 points in identifying individual phonemes. Particularly, he was most successful in identifying initial sounds and vowels found in the initial, medial, or ending positions. 


\subsection{Paula}

Paula was a 5-and-a-half-year-old Latina preschooler who was instructed in a general education classroom in Spanish by a bilingual teacher. There were two aides in the room, both of which were bilingual. At pretest, Paula had difficulty with identifying parts of a book; identifying letters, sounds, and words; and rhyming, as well as alliteration, initial sound identification, and segmenting words into phonemes. At posttest, in English, she was able to identify initial sounds, rhyme, and identify some letters (see Table 3). PA skills, as indicated by the PIPA, showed she was able to rhyme and segment words into syllables, as well as some at the individual phoneme level, and identify some letter sounds. She continued to have difficulty with alliteration, sound isolation, and identifying environmental print. On the FSF assessment, Paula increased her score by 3 points. Paula could successfully identify $/ \mathrm{p} /$, $/ \mathrm{s} /, / \mathrm{f} /, / \mathrm{b} /, / \mathrm{v} /$, and $/ \mathrm{ch} /$ in the initial position. Twice, she was able to identify $/ \mathrm{s} /$ and $/ \mathrm{l} /$ in the medial position.

\section{Discussion}

This study examined the use of native language to boost emergent literacy and PA skills of ELs who were having difficulty with literacy. The intervention showed that a targeted intervention, even for a short amount of time, can have a positive impact on children's emergent literacy skills. The findings support the importance of using systematic and explicit instructional routines, particularly with children having literacy difficulties, regardless of their language status. Additionally, although changes in scores from pretest to posttest were small, there were general gains over the four-week span, which showed a positive trend. Short interventions, such as this one, may be of more value to teachers who do not have access to interventionists. These types of short interventions allow the teacher to increase the skills of a greater number of students, as opposed to a longer intervention with fewer students.

It was not surprising to discover that the PA skill of syllable segmentation showed the most growth across children, since many of the intervention activities involved segmenting words into syllables. Likewise, when learning to blend and segment words, teaching sequences begin with syllables, then move on to onset-rime, and culminate at the individual phoneme level. Hence, results indicated that the children were beginning to master their ability to segment words, and possibly with continued instruction, would be able to do so at the phoneme level.

The findings from this study are in line with previous research, particularly for the use of native language instruction and its generalization into English [13]. It was interesting to note that 3 out of 4 children were instructed in a general education classroom in Spanish, but Ricardo was the only child who was instructed in a general education classroom in English. Ricardo's growth in both the Spanish and English measures could indicate that the language of classroom instruction does not necessarily hinder growth in a Spanish intervention. Additionally, the pre- and posttest results of this intervention demonstrate the cross-linguistic transfer of Spanish PA skills to support the development of phonological skills in English. For example, children were taught to break words into syllables during the intervention, which they were then able to show with English words. Although previous studies found mixed results for the use of native language instruction on English outcomes [17], this study shows a positive impact on both the Spanish and English outcomes of the children.

Although the results of the FSF did not show growth, the children's age difference may have played a role, particularly since the FSF is used during the winter and spring benchmark of the kindergarten year [49]. Both Ignacio and Ricardo were four years old when they participated in the intervention and would attend preschool programming for one additional year. On the other hand, both Paula and Manuel were five years old at the time and would be moving on to kindergarten in the fall. Under the umbrella of PA, phoneme segmentation is a more difficult skill. As young four-year-olds, Ignacio and Ricardo may have not yet had phoneme instruction, while Paula and Manuel may have had instruction at the phoneme level in preparation for kindergarten. 


\section{Implications and Limitations}

The findings of the study are important for a several reasons. First, they demonstrate how even a short intervention period is beneficial and promotes children's growth in emergent literacy and PA. Additionally, they show that native language instruction does not impede the development of English literacy skills, and through cross-linguistic transfer, can help children develop an understanding for literacy concepts in English. Also, targeting emergent literacy and PA can help children make gains in skills that are foundational for later reading success. By strengthening the foundational skills, teachers can help children ensure success in their reading development.

Finally, although the results are promising, there are a few limitations. The small sample size is a limitation which makes it hard to generalize results to the broader EL population. Increasing the number of students in a study such as this would help strengthen the results. Likewise, repeating this study with older children using randomized-control trials could bolster the research base for the use of native language instruction. Another limitation is the short time span between pretesting and posttesting, since the students may have remembered the items from the pretesting session, and thus done better on the posttest. To avoid this factor, alternate posttests should be used.

Author Contributions: Conceptualization, W.G. and M.T.H.; Data curation, W.G.; Formal analysis, W.G.; Writing—original draft, W.G. and M.T.H.

Funding: This research received no external funding.

Conflicts of Interest: The authors declare no conflict of interest.

\section{References}

1. The Number of Bilingual Kids in America Continues to Rise. Available online: https:/ / datacenter.kidscount. org/updates/show /184-the-number-of-bilingual-kids-in-america-continues-to-rise?utm_source=eblast\& utm_medium=email\&utm_campaign=KIDS-COUNT (accessed on 11 January 2018).

2. Richards-Tutor, C.; Baker, D.L.; Gersten, R.; Baker, S.K.; Smith, J.M. The effectiveness of reading interventions for English learners: A research synthesis. Except. Child. 2016, 82, 144-169. [CrossRef]

3. Pfost, M.; Hattie, J.; Dörfler, T.; Artelt, C. Individual differences in reading development a review of 25 years of empirical research on Matthew effects in reading. Rev. Educ. Res. 2013, 84, 203-244. [CrossRef]

4. Sanchez, C. English Language Learners: How Your State Is Doing. Available online: https://www.npr.org/ sections / ed/2017/02/23/512451228/5-million-english-language-learners-a-vast-pool-of-talent-at-risk (accessed on 18 October 2018).

5. Dolan, S. Missing out: Latino Students in America's Schools. Available online: http:/ / publications.unidosus. org/handle/123456789/1270 (accessed on 18 October 2018).

6. August, D.; Shanahan, L. Developing Literacy in Second-Language Learners: Report of the National Literacy Panel on Language Minority Children and Youth; National Literacy Panel on Language-Minority Children and Youth: Washington, DC, USA, 2006.

7. Maxwell, L.A.; Shah, N. Evaluating ELLs for special needs a challenge. Educ. Week 2012, 32.

8. Sullivan, A.L. Disproportionality in special education identification and placement of English language learners. Except. Child. 2011, 77, 317-334. [CrossRef]

9. Durgunoğlu, A.Y.; Goldenberg, C.N. Language and Literacy Development in Bilingual Settings; Guilford Press: New York, NY, USA, 2011; ISBN 9781606239544.

10. Verhoeven, L.T. Second language reading acquisition. In Handbook of Reading Research IV; Kamil, M., Pearson, D., Moje, E., Afflerbach, P., Eds.; Routledge: New York, NY, USA, 2011; pp. 661-683. ISBN 9780805853438.

11. Bialystok, E.; Luk, G.; Kwan, E. Bilingualism, biliteracy, and learning to read: Interactions among languages and writing systems. Sci. Stud. Read. 2005, 9, 43-61. [CrossRef]

12. Lindholm-Leary, K. Bilingual and biliteracy skills in young Spanish-speaking low-SES children: Impact of instructional language and primary language proficiency. Int. J. Biling. Educ. Biling. 2014, 17, 144-159. [CrossRef] 
13. Cárdenas-Hagan, E.; Carlson, C.D.; Pollard-Durodola, S.D. The cross-linguistic transfer of early literacy skills: The role of initial L1 and L2 skills and language of instruction. Lang. Speech Hear. Serv. Sch. 2007, 38, 249-259. [CrossRef]

14. Carlo, M.S.; Barr, C.D.; August, D.; Calderón, M.; Artzi, L. Language of instruction as a moderator for transfer of reading comprehension skills among Spanish-speaking English language learners. Biling. Res. J. 2014, 37, 287-310. [CrossRef]

15. Klingner, J.K.; Artiles, A.J.; Barletta, L.M. English language learners who struggle with reading language acquisition or LD? J. Learn. Disabil. 2006, 39, 108-128. [CrossRef] [PubMed]

16. Goldenberg, C. Reading instruction for English language learners. In Handbook of Reading Research IV; Kamil, M., Pearson, D., Moje, E., Afflerbach, P., Eds.; Routledge: New York, NY, USA, 2011; pp. 661-683. ISBN 9780805853438.

17. Vaughn, S.; Linan-Thompson, S.; Mathes, P.; Cirino, P.; Carlson, C.; Pollard-Durodola, S.; Francis, D. Effectiveness of Spanish intervention for first-grade English language learners at risk for reading difficulties. J. Learn. Disabil. 2006, 39, 56-73. [CrossRef] [PubMed]

18. Vaughn, S.; Linan-Thompson, S.; Mathes, P.; Carlson, C.; Cardenas Hagan, E.; Pollard-Durodola, S.; Francis, D. Effectiveness of a Spanish intervention and an English intervention for English-language learners at risk for reading problems. Am. Educ. Res. J. 2006, 43, 449-487. [CrossRef]

19. Linan-Thompson, S.; Bryant, D.P.; Dickson, S.V.; Kouzekanani, K. Spanish literacy instruction for at-risk kindergarten students. Remedial Spec. Educ. 2005, 26, 236-244. [CrossRef]

20. Baker, D.L.; Park, Y.; Baker, S.K.; Basaraba, D.L.; Kame'enui, E.J.; Beck, C.T. Effects of paired bilingual reading program and an English-only program on the reading performance of English learners in grades 1-3. J. Sch. Psychol. 2012, 50, 737-758. [CrossRef] [PubMed]

21. Lonigan, C.J.; Shanahan, T. Developing Early Literacy: Report of the National Early Literacy Panel. Executive Summary. A Scientific Synthesis of Early Literacy Development and Implications for Intervention. Available online: https: / / eric.ed.gov / ?id=ED508381 (accessed on 18 October 2018).

22. Restrepo, M.; Towle-Harmon, M. Addressing emergent literacy in English-language learners' skills. ASHA Lead. 2008, 13, 10-13. [CrossRef]

23. Ezell, H.K.; Justice, L.M. Shared Storybook Reading: Building Young Children's Language and Emergent Literacy Skills; PH Brookes Pub: Baltimore, MD, USA, 2005; ISBN 9781557668004.

24. Chan, L.L.; Sylva, K. Exploring emergent literacy development in a second language: A selective literature review and conceptual framework for research. J. Early Child. Lit. 2014, 15, 3-36. [CrossRef]

25. Gersten, R.; Baker, S.K.; Shanahan, T.; Linan-Thompson, S.; Collins, P.; Scarcella, R. Effective Literacy and English Language Instruction for English Learners in the Elementary Grades: A Practice Guide; NCEE Report No. 2007-4011; U.S. Department of Education, Institute of Education Sciences, National Center for Education Evaluation and Regional Assistance: Washington, DC, USA, 2007.

26. Hilbert, D.D.; Eis, S.D. Early intervention for emergent literacy development in a collaborative community pre-kindergarten. Early Child. Educ. J. 2014, 42, 105-113. [CrossRef]

27. Justice, L.M.; McGinty, A.S.; Piasta, S.B.; Kaderavek, J.N.; Fan, X. Print-focused read-alouds in preschool classrooms: Intervention effectiveness and moderators of child outcomes. Lang. Speech Hear. Serv. Sch. 2010, 41, 504-520. [CrossRef]

28. Durgunoğlu, A.Y. Cross-linguistic transfer in literacy development and implications for language learners. Ann. Dyslexia 2002, 52, 189-204. [CrossRef]

29. Bravo-Valdivieso, L.; Villalón, M.; Orellana, E. Predictibilidad del rendimiento en la lectura: Una investigacion de seguimiento entre primer y tercer ano. Revista Latinoamericana de Psicología 2006, 38, 9-20.

30. Dickinson, D.K.; McCabe, A.; Clark-Chiarelli, N.; Wolf, A. Cross-language transfer of phonological awareness in low-income Spanish and English bilingual preschool children. Appl. Psycholinguist. 2004, 25, 323-347. [CrossRef]

31. Páez, M.M.; Tabors, P.O.; López, L.M. Dual language and literacy development of Spanish-speaking preschool children. J. Appl. Dev. Psychol. 2007, 28, 85-102. [CrossRef] [PubMed]

32. Raynolds, L.B.; Lopez-Velasques, A.; Olivo Valentin, L.E. Exploring English and Spanish rhyme awareness and beginning sound segmentation skills in prekindergarten Spanish-speaking English learners. Read. Writ. 2017, 30, 719-737. [CrossRef] 
33. Leafstedt, J.M.; Gerber, M.M. Crossover of phonological processing skills a study of Spanish-speaking students in two instructional settings. Remedial Spec. Educ. 2005, 26, 226-235. [CrossRef]

34. Lovett, M.W.; De Palma, M.; Frijters, J.; Steinbach, K.; Temple, M.; Benson, N.; Lacerenza, L. Interventions for reading difficulties a comparison of response to intervention by ell and efl struggling readers. J. Learn. Disabil. 2008, 41, 333-352. [CrossRef] [PubMed]

35. O'Shaughnessy, T.E.; Swanson, H.L. A comparison of two reading interventions for children with reading disabilities. J. Learn. Disabil. 2000, 33, 257-277. [CrossRef] [PubMed]

36. Lesaux, N.K.; Siegel, L.S. The development of reading in children who speak English as a second language. Dev. Psychol. 2003, 39, 1005-1019. [CrossRef] [PubMed]

37. Ehri, L.C.; Nunes, S.R.; Stahl, S.A.; Willows, D.M. Systematic phonics instruction helps students learn to read: Evidence from the National Reading Panel's meta-analysis. Rev. Educ. Res. 2001, 71, 393-447. [CrossRef]

38. Hammer, C.S.; Miccio, A.W. Early language and reading development of bilingual preschoolers from low-income families. Top. Lang. Disord. 2006, 26, 322-337. [CrossRef] [PubMed]

39. Ballard, W.S.; Tighe, P.L.; Dalton, E.F. IDEA Oral Language Proficiency Test; Ballard \& Tighe: Brea, CA, USA, 1980.

40. Farver, J.M.; Nakamoto, J.; Lonigan, C.J. Assessing preschoolers' emergent literacy skills in English and Spanish with the Get Ready to Read! screening tool. Ann. Dyslexia 2007, 57, 161-178. [CrossRef] [PubMed]

41. Dodd, B.; Crosbie, S.; McIntosh, B.; Teitzel, T.; Ozanne, A. The Pre-Reading Inventory of Phonological Awareness: Manual; Psychological Corporation: Bloomington, MN, USA, 2003.

42. Cummings, K.D.; Baker, D.L.; Good, R.H. Indicadores Dinámicos del Éxito en la Lectura 7a edicion. Available online: http:/ / dibels.uoregon.edu/ (accessed on 18 October 2018).

43. Baker, D.L.; Cummings, K.D.; Good, R.H.; Smolkowski, K. Indicadores Dinámicos del Éxito in la Lectura (IDEL): Summary of Decision Rules for Intensive, Strategic, and Benchmark Instructional Recommendations in Kindergarten through Third Grade; Technical Report No.1; Dynamic Measurement Group: Eugene, OR, USA, 2007.

44. Williams, S. Sali de Paseo; Live Oak Media: Pine Plains, NY, USA, 1996.

45. Carle, E. El canguro tiene mamá? HarperCollins: New York, NY, USA, 2000.

46. Elhert, L. A sembrar sopa de verduras; Wright Group: Chicago, IL, USA, 2011.

47. Jordan, H.J. Como crece una semilla; Harper Collins: New York, NY, USA, 2006.

48. Suggate, S.P. A meta-analysis of the long-term effects of phonemic awareness, phonics, fluency, and reading comprehension interventions. J. Learn. Disabil. 2016, 49, 77-96. [CrossRef] [PubMed]

49. Goffreda, C.T.; DiPerna, J.C. An empirical review of psychometric evidence for the dynamic indicators of basic early literacy skills. Sch. Psychol. Rev. 2010, 39, 463-483. 